\title{
Dopamine D4 Receptor Exon III Polymorphism, Adverse Life Events and Personality Traits in a Nonclinical German Adult Sample
}

\author{
Iris Reiner ${ }^{a} \quad$ Gottfried Spangler ${ }^{b}$ \\ ${ }^{a}$ Clinic for Psychosomatic Medicine and Psychotherapy, Johannes Gutenberg University of Mainz, Mainz, and \\ ${ }^{b}$ Institute of Psychology, University of Erlangen Nuremberg, Erlangen, Germany
}

\section{Key Words}

Dopamine D4 receptor gene - Adverse life events •

Personality · Gene-environment interaction

\begin{abstract}
Personality and temperament embrace a wide area of both psychological and behavioral processes which are also based on disposition. A functional polymorphism in exon III of the dopamine D4 receptor gene (DRD4) has been a highly suspect genetic marker for personality in spite of ambiguous results. The present study aimed to further elucidate the relationship between DRD4, negative life events and personality in a representative nonclinical sample. Hundred sixty-seven Germans completed the NEO Five-Factor Inventory, the Tridimensional Personality Questionnaire and the California Adult Q-Sort. A factor analysis revealed 3 factors: emotional stability, social orientation and impulsivity. DNA from buccal cells was genotyped for the DRD4 variable-number tandemrepeat exon III polymorphism with respect to presence versus absence of the DRD4 7-repeat allele. Adverse life events were assessed by means of the Adverse Life Events Scale. Men carrying the DRD4 7-repeat allele were more impulsive than those without. Male 7-repeat carriers were more emotionally instable than others, but only when they experienced a large amount of negative life events. No genotypepersonality relationships were found for women. The results
\end{abstract}

indicate gender-specific influences of the DRD4 gene on human behavior and invite researchers to further investigate gene-environment correlations on personality traits.

Copyright $\odot 2010$ S. Karger AG, Basel

\section{Introduction}

Personality is related to a person's behavior as an outer appearance as well as to inner-psychic processes such as thoughts [1]. The domain of temperament has been described as 'a subset of the more general area of personality' [2, p. 108]. Thus, it is nearly impossible to strictly distinguish temperament from adult personality [3] as personality 'grows out' of temperament. Within the last decades, behavior-genetic research provided evidence that temperament and personality are influenced by both genetic and environmental factors [4, table III]. However, behavior-genetic studies only provide information about the relative influence of all genes as opposed to the environment and do not reveal which genes are involved in specific behaviors.

In 1996, 2 publications in Nature Genetics first reported the discovery of an association between the DRD4 variable number tandem repeat (VNTR) polymorphism in the exon III 7-repeat allele and the personality trait novelty seeking measured with the Tridimensional Per-

\section{KARGER}

Fax +4161306 1234

E-Mail karger@karger.ch

www.karger.com
(C) 2010 S. Karger AG, Basel

0302-282X/11/0631-0052\$38.00/0

Accessible online at:

www.karger.com/nps
Dr. phil. Dipl.-Psych. Iris Reiner

Klinik und Poliklinik für Psychosomatische Medizin und Psychotherapie

Johannes Gutenberg-Universität, Untere Zahlbacher Strasse 8

DE-55131 Mainz (Germany)

Tel. +49 613117 8124, Fax +49 613117 5563, E-Mail iris.reiner@ unimedizin-mainz.de 
sonality Questionnaire as well as high extraversion and low conscientiousness as measured with the NEO FiveFactor Inventory $[5,6]$. An extensive number of studies followed trying to confirm these findings differing in methods as well as in sample size, sex, ethnicity and age of the participants [7, table III]. The results, however, were very inconsistent $[8-12]$.

Kluger et al. [13] conducted a meta-analysis of 20 studies on the association between the DRD4 VNTR polymorphism and novelty seeking. The authors concluded that, on average, there was no relationship and invited researchers to search for moderators and potential interactions with other variables, such as environmental stressors. Thus, the lack of studying environmental stressors may be one reason among others that previous findings have given such diverse answers to the question at hand, i.e. how the DRD4 7-repeat allele is associated with personality. In fact, recent studies have reported gene-environment interactions that shape behavior and personality development, conceptualizing environmental variables as risk factors such as insensitive parenting, stress and exposure to trauma $[14,15$, for review see 16]. Two further meta-analyses on DRD4 polymorphisms in relation to novelty seeking lead to contradicting results: Schinka et al. [17] provided evidence for a small effect of the DRD4 VNTR 'long alleles' on novelty seeking, while a recent meta-analysis by Munafò et al. [18] suggested that there is no systematic association between the DRD4 VNTR polymorphism and approach-related traits. Researchers agree that the heterogeneity in earlier findings might be due to the fact that studies differ in methodology, sample size and sex [13, 18-23].

Hitherto, the relationship between the DRD4 7-repeat allele and novelty seeking as well as related traits remains unclear. Therefore, the present study aims to further elucidate the relationship between DRD4 VNTR polymorphism and personality traits in a representative German sample of nonclinical males and females. In order to increase the construct validity, we chose 3 different methods to assess personality. Moreover, considering possible environmental stressors influencing personality, we included the assessment of adverse life events to explore potential gene-environment interactions.

\section{Materials and Methods}

\section{Sample}

The participants were (pairs of) parents of children being involved in the Regensburg Longitudinal Study IV. This is an ongoing study that started in 1993. Contact information from the ini- tial total sample of $n=106$ families was gained from the civil registry office of Regensburg in order to recruit parents of children born between March and September 1992. Study participation was voluntary and based on written consent forms. In the last waves of data collection in 2005, 87 mothers and 80 fathers aged 32-61 years $(\mathrm{M}=42.8, \mathrm{SD}=4.9)$ from the initial 106 families participated. All participants were German citizens. Females were significantly younger in the study than men, $\mathrm{t}(144.9)=4.05, \mathrm{p}=$ 0.00 . The majority of the study participants had lower secondary or secondary education $(67.5 \%)$, were working full- or part-time $(84.2 \%)$ and were married (83.3\%). The distribution of major sociodemographic markers demonstrates reasonable representativeness for Germany.

\section{Assessment of Adverse Life Events}

Adverse life events were assessed by means of the Adverse Life Events Scale. Inspired by items of the 'life history calendar' [24], the Adverse Life Events Scale is a 19 -item procedure to assess adverse life events relating to partnership, family, work and health. It took about $15 \mathrm{~min}$ to administer. The subjects were asked whether and when the respective adverse event had occurred (e.g. major health problems, divorce and layoff). One subject was not interviewed. The measure for adverse life events was calculated as the sum of identified events with a possible range between 0 and 19.

\section{Personality Assessment}

Personality was assessed by means of 3 different self-report instruments to ensure construct validity.

- The German self-report version of the NEO Five-Factor Inventory adapted by Borkenau and Ostendorf [25] is a 60-item questionnaire for the measurement of the big 5 personality dimensions openness, conscientiousness, extraversion, agreeableness and neuroticism. Each dimension is represented by 12 items and to be rated along a 5-point Likert scale reaching from 'strongly agree' to 'strongly disagree'.

- A German translation of Block's [26] California Adult Q-Set was used to assess the dimensions ego-control and ego-resiliency [27]. The participants were asked to describe themselves by sorting 100 statements about personality and social characteristics into a fixed quasinormal distribution. Correlations between an individual's personality description and pre-existing, conceptual prototypes [28] indicate the similarity degree between the individual and the prototype.

- The German version of Cloninger's Tridimensional Personality Questionnaire [29] is a 98-item questionnaire for the measurement of Cloninger's 3 temperament dimensions novelty seeking, harm avoidance and reward dependence. The items are rated on a dichotomy scale (yes-no format).

\section{Genotyping}

Genotyping was performed without knowledge of phenotype information. Gene analyses were conducted by Dr. Monika Johann at the Institute of Psychiatry at the University of Regensburg, Germany. Genomic DNA was collected and isolated from buccal swabs using published procedures [30]. One subject could not be genotyped.

DNA samples were processed in an Eppendorf Mastercycler gradient PCR system (Eppendorf, Hamburg, Germany). After an initial 5-min denaturation at $95^{\circ} \mathrm{C}$, the protocol comprised 
40 cycles of $45 \mathrm{~s}$ at $95^{\circ} \mathrm{C}, 45 \mathrm{~s}$ at $65^{\circ} \mathrm{C}$ touch-down and $90 \mathrm{~s}$ at $72^{\circ} \mathrm{C}$ plus a final elongation step of $7 \mathrm{~min}$ at $72^{\circ} \mathrm{C}$. For exon III 48-bp VNTR polymorphism in DRD4 the primers were as follows: 5'-GCG ACT ACG TGG TCT ACT CG-3' and 5'-AGG ACC CTC ATG GCC TTG-3'. The PCR cycling conditions were $15 \mathrm{~min}$ at $95^{\circ} \mathrm{C}$ followed by 35 cycles of $45 \mathrm{~s}$ at $95^{\circ} \mathrm{C}$ (denaturation), $30 \mathrm{~s}$ at $50^{\circ} \mathrm{C}$ (annealing) and $30 \mathrm{~s}$ at $72^{\circ} \mathrm{C}$ (elongation) with a final extension for $7 \mathrm{~min}$ at $72^{\circ} \mathrm{C}$ using a Multicycler PTC 200 gradient machine (Biozym Diagnostik, Germany). PCR products were separated by $2.0 \%$ agarose gel electrophoresis and stained with ethidium bromide for UV visualization. The PCR reaction yielded distinct bands at $380 \mathrm{bp}$ (2 repeats), $428 \mathrm{bp}$ (3 repeats), $476 \mathrm{bp}$ (4 repeats), $524 \mathrm{bp}$ (5 repeats), $572 \mathrm{bp}$ (6 repeats), 620 bp (7 repeats), 668 bp ( 8 repeats), 716 bp ( 9 repeats) and 784 bp (10 repeats) [31].

The main genotypes $(2 / 2,2 / 4,2 / 7,4 / 4,4 / 7,7 / 7$ and others $)$ were in Hardy-Weinberg equilibrium $\chi^{2}(9, \mathrm{n}=166)=6.84$, nonsignificant.

The DRD4 genotypes were grouped on the basis of the presence (in the following also indicated by DRD4.7+) versus the absence (in the following also indicated by DRD4.7-) of the 7-repeat allele. To facilitate the comparison with previous reports, DRD4.7+ versus DRD4.7- grouping was preferred to the short versus long allele dichotomization. Also, Wang et al. [32] cautioned against the short versus long grouping due to the nonlinear nature of the binding properties of alleles of different length.

\section{Statistical Analysis}

In order to test influences of DRD4 genotypes and adverse life events on personality, a multivariate analysis of variance was conducted in the first step followed by univariate analyses of variance investigating tendency and significant effects in a second step. Effect sizes were indicated by using $\eta^{2}$. Duncan's multiple-group comparison tests were used for post hoc testing. A 2 -sided $p$ value $\leq 0.05$ was considered as statistically significant. $\alpha$ errors $>5 \%$ up to a maximum of $\mathrm{p}=0.10$ were reported as tendencies. Additionally, post hoc power analyses using $\mathrm{G}^{*}$ Power software [33] were performed. The statistical power ranged from 0.74-0.96. Power values $<0.74$ are reported.

\section{Results}

\section{Factor Analysis}

A total of 10 personality scales resulted from the 3 personality procedures. Factor analysis was conducted across these scales for 2 reasons: (a) to uncover dimensions of personality as measured with 3 different instruments, and (b) to reduce the fairly large number of scales and to avoid multiple comparisons in consequence of multiple personality variables. Factor analysis (principal component analysis, Varimax rotation with Kaiser normalization, eigenvalue $>1$ ) revealed a 3 -factor structure.

The first factor, 'emotional stability', mainly captures aspects of low anxiety and depression due to highly negative loadings on harm avoidance $(-0.88)$ and neuroti- cism (-0.87) and high positive loadings on ego-resiliency (0.82) and extraversion (0.61). Subjects with high factor values generally remain stable in times of stress, tend to stay calm and objective when facing challenging or upsetting situations and are less affected by mood variations. Emotionally instable subjects, however, tend to have a general anxious and distrustful attitude towards the environment and towards themselves.

The second factor, 'social orientation', primarily includes the dimensions reward dependence (0.85), agreeableness (0.71) and openness (0.55). These personality dimensions describe a tendency to react sensitively to signals of the social environment and to align with them. Subjects with high values on 'social orientation' tend to avoid conflicts and are rather communicative and guided by social interactions. Contrary, subjects with low values on 'social orientation' prefer to be alone; it is easier for them to make decisions independently from environmental judgments.

The third factor, 'impulsivity', comprises high loadings on novelty seeking (0.89) and low ego-control (0.75). Both dimensions reflect the direct expression of impulses, motivations and affects. Furthermore, factor 3 is characterized by a low degree of conscientiousness $(-0.62)$, a construct that involves low impulsivity as well as lowtempered and orderly behavior. Subjects with high values on 'impulsivity' tend to act spontaneously and with less consideration than others. They are predisposed to rapid reactions to internal or external stimuli.

\section{Descriptive Statistics and Preliminary Analyses}

The frequency of adverse life events ranged from 1 to $13(\mathrm{M}=5.8, \mathrm{SD}=2.4)$. A sex comparison by analysis of variance revealed an effect for sex which, however, only approached significance, $F(1,164)=3.34, p=0.07, \eta^{2}=$ 0.02 , power $=0.45$. The findings indicate that men $(\mathrm{M}=$ $6.1, \mathrm{SD}=2.3$ ) experienced more adverse life events than women $(M=5.5, S D=2.5)$. There was no significant correlation between adverse life events and age. For further analyses, the Adverse Life Events Scale was split at the median into 2 groups of subjects with a low or high frequency of adverse life events $(1-5 / \mathrm{n}=88$ and $6-13 / \mathrm{n}=78$, respectively).

The values for the 3 personality factors were output as regression scores with a mean of 0 and SD of 1 for all 3 personality factors in the total sample. Regarding sex differences, univariate comparisons showed that the subjects differed significantly on emotional stability, $\mathrm{F}(1$, $165)=5.95, p=0.02, \eta^{2}=0.04$, and social orientation, $F(1$, $165)=14.76, \mathrm{p}=0.00, \eta^{2}=0.08$, but not on impulsivity. 
Women were less emotionally stable $(\mathrm{M}=-0.17, \mathrm{SD}=1.0)$ and more socially oriented $(\mathrm{M}=0.27, \mathrm{SD}=0.76)$ than men $(\mathrm{M}=0.19, \mathrm{SD}=0.97$ and $\mathrm{M}=-0.29, \mathrm{SD}=1.13$, respectively). Correlation analyses revealed no significant associations between age and emotional stability, or age and social orientation. However, impulsivity showed significant relations with age, $\mathrm{r}(167)=-0.19, \mathrm{p}=0.01$, with older subjects being less impulsive. As a consequence of the associations between personality measures with sex and age, age was considered as a covariate in all following analyses of variance including impulsivity, and sex was considered as an additional independent variable in all following analyses. Main effects for sex on personality will not be repeatedly reported.

Regarding genotypes, there were 52 subjects (31.3\%) with the DRD4.7+ genotype and 114 (68.7\%) with the DRD4.7- genotype. The DRD4 genotype distributions differed significantly with respect to sex, with more women carrying the 7-repeat allele, $\chi^{2}(1, \mathrm{n}=166)=5.11$, $\mathrm{p}=0.02$.

As the present sample consisted of marital couples (mothers and fathers of children from the Regensburg Longitudinal Study IV), a potential influence of assortative mating regarding personality was tested. There was no significant correspondence between partners' personality. Also, there were no associations between DRD4 genotype (7+/7-) and the frequency of adverse life events.

\section{Prediction of Personality by DRD4 and}

\section{Adverse Life Events}

In the first step and in order to avoid a high number of testing and $\alpha$-inflation, an overall multivariate analysis of variance was conducted entering emotional stability, social orientation and impulsivity as dependent variables and sex $($ male/female $) \times$ DRD4 genotype $(7+/ 7-) \times$ adverse life events (low/high) as independent variables. A highly significant main effect for sex, $\mathrm{F}(3,155)=5.72$, $\mathrm{p}=0.00, \eta^{2}=0.10$, and for adverse life events, $\mathrm{F}(3,155)=$ $3.46, p=0.02, \eta^{2}=0.06$, on personality was found. Moreover, the multivariate analysis of variance yielded a tendency to 2-way interaction between DRD4 and sex, F(3, $155)=2.16, p=0.09, \eta^{2}=0.04$, as well as a tendency to 3 -way interaction effect between adverse life events, DRD4 genotype and sex, $\mathrm{F}(3,155)=2.25, \mathrm{p}=0.08, \eta^{2}=$ 0.04 , regarding personality.

In the second step and in order to test the predictability of personality by DRD4 genotypes and adverse life events more specifically, a sex (male/female) $\times$ DRD4 genotype (7+/7-) $\times$ adverse life events (low/high) analysis of variance was conducted separately for each of the 3 personality factors. While there were no effects for social orientation, significant effects were found for impulsivity and emotional stability. Table 1 presents means and SD for the 3 personality factors with respect to the DRD4 genotype in the total sample as well as separately for males and females.

Regarding impulsivity there was a significant main effect for adverse life events, $F(1,156)=6.11, p=0.01, \eta^{2}=$ 0.04 , and a 2 -way interaction between DRD4 and sex, $\mathrm{F}(1$, $162)=4.44, p=0.04, \eta^{2}=0.03$, power $=0.61$. Subjects with a high frequency of adverse life events were found to be more impulsive $(\mathrm{M}=0.21, \mathrm{SD}=0.98)$ than those who experienced less adverse life events $(\mathrm{M}=-0.19, \mathrm{SD}=0.99)$. Duncan post hoc comparisons regarding the interaction between DRD4 and sex revealed that a genetic influence on impulsivity was only given for male subjects. While there were no relations between DRD4 and impulsivity in female subjects, men carrying the 7-repeat allele were significantly more impulsive than those without it (Duncan, $\mathrm{p} \leq 0.05$; see table 1 ).

Regarding emotional stability there was a significant 3-way interaction between adverse life events, DRD4 genotype and sex, $\mathrm{F}(1,157)=4.93, \mathrm{p}=0.03, \eta^{2}=0.03$, power $=0.61$. As demonstrated in figure 1 , men carrying the DRD4 7-repeat allele showed a low emotional stability, but only when they had experienced a large amount of adverse life events (Duncan post hoc tests).

\section{Discussion}

The investigation of the relationship between the DRD4 gene and personality brought out important sexspecific findings: while no associations between personality and genotypes were found in females, the DRD4 7-repeat allele was related to impulsivity in men. Additionally, male subjects who carried the DRD4 7-repeat allele were less emotionally stable than those without it when having experienced high occurrence of adverse life events. Independent of sex, high occurrence of adverse life events was associated with higher impulsivity. The following subsections discuss these results in detail.

Our findings confirm previously reported associations between high impulsivity (and related traits) and the presence of the DRD4 7-repeat allele in male but not in female subjects $[34,35]$. Based on the assumption that higher dopaminergic stimulation in specific brain areas is associated with impulsive behavior $[36,37]$, the relation between DRD4 7-repeat and impulsivity is consistent with current theoretical concepts of the regulation of the 
Fig. 1. Emotional stability (means and standard errors) depending on adverse life events occurrence and DRD4 genotype. a Males. b Females.

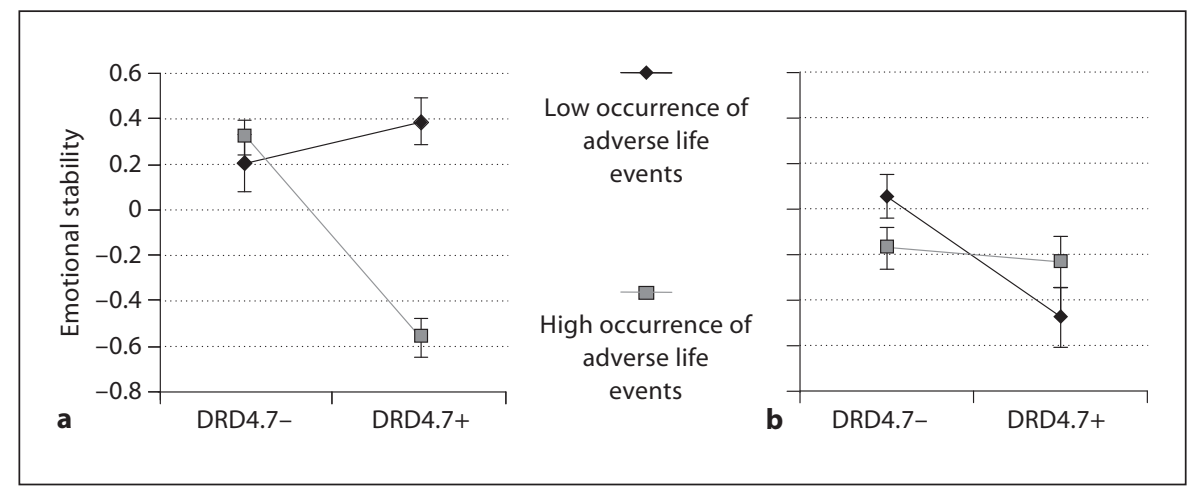

Table 1. Personality and DRD4 genotype: means and SD

\begin{tabular}{lrrr}
\hline & $\begin{array}{l}\text { Total } \\
(\mathrm{n}=166)\end{array}$ & $\begin{array}{l}\text { Males } \\
(\mathrm{n}=79)\end{array}$ & $\begin{array}{l}\text { Females } \\
(\mathrm{n}=87)\end{array}$ \\
\hline $\begin{array}{l}\text { Emotional stability } \\
\text { DRD4.7- }\end{array}$ & $0.08 \pm 1.06$ & $0.30 \pm 0.99$ & $-0.17 \pm 1.08$ \\
$\quad \begin{array}{l}\text { DRD4.7+ } \\
\text { Social orientation }\end{array}$ & $-0.18 \pm 0.85$ & $-0.17 \pm 0.83$ & $-0.19 \pm 0.87$ \\
DRD4.7- & $-0.02 \pm 1.02$ & $-0.30 \pm 0.17$ & $0.30 \pm 0.70$ \\
DRD4.7+ & $0.03 \pm 0.96$ & $-0.35 \pm 1.06$ & $0.23 \pm 0.86$ \\
Impulsivity & & & \\
DRD4.7- & $-0.04 \pm 1.04$ & $-0.24 \pm 0.97^{\mathrm{a}}$ & $0.18 \pm 1.07^{\mathrm{b}}$ \\
DRD4.7+ & $0.08 \pm 0.93$ & $0.34 \pm 0.91^{\mathrm{b}}$ & $-0.06 \pm 0.91$ \\
\hline
\end{tabular}

a, b Different letters indicate statistically significant differences (Duncan, $\mathrm{p} \leq 0.05$ ) between the subgroups.

DRD4 gene and dopamine transmission in the brain. Yet, this association was not found in female subjects, although the 2 sexes did not differ in their mean level of impulsivity. Possibly, dopamine - the neurotransmitter influenced by the DRD4 gene - might work differently in male than in female brains, which may lead to sex-specific phenotypical outcomes. Dewing et al. [38] identified a specific gene on the $\mathrm{Y}$ chromosome that has a sex-specific effect on dopamine-secreting neurons. Also, several studies have shown that the distribution of dopamine in the brain has been linked to sex differences in the regulation of gonadotropic hormones [e.g. 39]. Interestingly, the DRD4 7-repeat genotype could be identified as a risk factor for emotional instability, again only in men. Compared to men without the 7-repeat allele - who appear to be rather unaffected by high occurrence of adverse life events - those with the 7-repeat allele dropped significantly in their emotional stability when having experi- enced a large amount of negative life events. Previously, the DRD4 gene had also been associated with mood disorders in clinical samples $[40,41]$. In line with the proposal of Caspi et al. [42] of gene-environment interplay in the development of psychopathology, our findings suggest that carrying the 7-repeat allele might be, especially in combination with negative life events, a risk factor for the development of emotion-related disorders such as depression.

Finally, independent of sex, high occurrence of adverse life events was associated with higher impulsivity. This relation had previously been found in a drug addiction sample [43]. Other studies suggest that impulsivity is associated with risk-taking behavior, higher divorce rate and unhealthy behavior $[44,45]$. Empirically and theoretically, extremely high 'impulsivity' and related personality concepts have been linked with a greater risk for drug abuse, perilous behavior and personality disorders [e.g. 45, 46].

Our findings confirm these previously reported associations and suggest that impulsive behavior might lead to a higher involvement in negative life events across different areas.

Several strengths and limitations of the present study need to be acknowledged. One of the strengths is that we used a sample of white European males and females only instead of a heterogenic sample regarding ethnicity. Our sample was representative and corresponded to the socioeconomic status of a nonclinical German population. Unlike in many studies investigating genetic markers and psychological variables [e.g. 6, 47], our sample did not consist of students recruited from universities. However, our study is limited because of its relatively small sample size and replication is needed in a larger sample.

Another advantage of the present study is that it does not rely on only 1 measurement but assessed personality 
with 3 different well-known instruments with various theoretical backgrounds. Moreover, the combination of Q-Sort and questionnaire data additionally increased the construct validity. Furthermore, in order to consider possible environmental stressors influencing personality, we included the assessment of adverse life events to explore potential gene-environment interactions regarding the association between the DRD4 7+/- genotypes and personality. With the purpose of investigating environmental influences on gene-personality associations more extensively, the nature and age in which the life events occurred should be taken into account in future studies.

The correlational design of the present study has implications for the interpretation of causal relationships. Longitudinal studies are needed to further establish causal relations between personality, genetic markers and adverse life events.
The results of our study suggest sex-specific influences of DRD4 on personality. In order to elucidate sex differences in functional significance between the DRD4 gene and personality on the dopamine system, more research is needed that includes brain imaging techniques and possible other psychobiological influence variables such as gonadal hormones. Finally, bearing in mind that genetic studies and single association studies in particular underlie the high risk to report false-positive findings [48], our results must be interpreted with caution. Thus, it is not permissible to propose the DRD4 as a 'gene for impulsivity'. Generally, it is strongly recommended to give up on such statements, as most traits and disorders are multifactorial and can only be fully understood in the interplay of multiple genes, proteins and environmental factors.

\section{References}

1 Funder DC: Personality. Annu Rev Psychol 2001;52:197-221.

2 Rothbart MK, Bates JE: Temperament; in Damon W, Eisenberg N (eds): Handbook of Child Psychology, ed 5. New York: Wiley, 1998, vol 3: Social, Emotional, and Personality Development, pp 105-176.

3 Strelau J: The concept and status of trait in research on temperament. Eur J Personality 2001; 15:311-325.

4 Bouchard J, Thomas J., Loehlin JC: Genes, evolution, and personality. Behav Genet 2001;31:243.

5 Benjamin J, Li L, Patterson C, Greenberg BD, Murphy DL, Hamer DH: Population and familial association between the D4 dopamine receptor gene and measures of novelty seeking. Nat Genet 1996;12:81-84.

6 Ebstein RP, Novick O, Umansky R, Priel B, Osher Y, Blaine D, Bennett ER, Nemanov L, Katz M, Belmaker RH: Dopamine D4 receptor (D4DR) exon III polymorphism associated with the human personality trait of novelty seeking. Nat Genet 1996;12:78-80.

7 Savitz JB, Ramesar RS: Genetic variants implicated in personality: a review of the more promising candidates. Am J Med Genet B Neuropsychiatr Genet 2004;131:20-32.

8 Benjamin J, Osher Y, Kotler M, Gritsenko I, Nemanov L, Belmaker RH, Ebstein RP: Association between tridimensional personality questionnaire (TPQ) traits and three functional polymorphisms: dopamine receptor D4 (DRD4), serotonin transporter promoter region (5-HTTLPR) and catechol O-methyltransferase (COMT). Mol Psychiatry 2000;5:96-100.
9 Ebstein RP, Nemanov L, Klotz I, Gritsenko I, Belmaker RH: Additional evidence for an association between the dopamine D4 receptor (D4DR) exon III repeat polymorphism and the human personality trait of novelty seeking. Mol Psychiatry 1997;2:472-477.

10 Ono Y, Manki H, Yoshimura K, Muramatsu T, Mizushima H, Higuchi S, Yagi G, Kanba S, Asai M: Association between dopamine D4 receptor (D4DR) exon III polymorphism and novelty seeking in Japanese subjects. Am J Med Genet 1997;74:501-503.

11 Kuhn KU, Meyer K, Nothen MM, Gansicke M, Papassotiropoulos A, Maier W: Allelic variants of dopamine receptor D4 (DRD4) and serotonin receptor 5HT2c (HTR2c) and temperament factors: replication tests. Am J Med Genet 1999;88:168-172.

12 Strobel A, Spinath FM, Angleitner A, Riemann R, Lesch K-P: Lack of association between polymorphisms of the dopamine $\mathrm{D}_{4}$ receptor gene and personality. Neuropsychobiology 2003;47:52-56.

13 Kluger AN, Siegfried Z, Ebstein RP: A metaanalysis of the association between DRD4 polymorphism and novelty seeking. Mol Psychiatry 2002;7:712-717.

14 Dragan WL, Oniszczenko W: The association between dopamine D4 receptor exon III polymorphism and intensity of PTSD symptoms among flood survivors. Anxiety Stress Coping 2009;22:483-495.

15 Propper C, Willoughby M, Halpern CT, Carbone MA, Cox M: Parenting quality, DRD4, and the prediction of externalizing and internalizing behaviors in early childhood. Dev Psychobiol 2007;49:619-632.
16 Rutter M: Genes and Behavior: Nature-Nurture Interplay Explained. Malden, Blackwell Publishing, 2006.

17 Schinka JA, Busch RM, Robichaux-Keene N: A meta-analysis of the association between the serotonin transporter gene polymorphism (5-HTTLPR) and trait anxiety. Mol Psychiatry 2004;9:197-202.

18 Munafò MR, Yalcin B, Willis-Owen SA, Flint J: Association of the dopamine D4 receptor (DRD4) gene and approach-related personality traits: meta-analysis and new data. Biol Psychiatry 2007;62:364-368.

19 Benjamin J, Ebstein RP, Belmaker RH: Personality genetics, 2002. Isr J Psychiatry Relat Sci 2002;39:271-279.

20 Munafò MR, Clark TG, Moore LR, Payne E, Walton R, Flint J: Genetic polymorphisms and personality in healthy adults: a systematic review and meta-analysis. Mol Psychiatry 2003;8:471-484.

21 Noblett KL, Coccaro EF: Molecular genetics of personality. Curr Psychiatry Rep 2005;7: 73-80.

22 Schinka JA, Letsch EA, Crawford FC: DRD4 and novelty seeking: results of meta-analyses. Am J Med Genet 2002;114:643-648.

23 Van Gestel S, Van Broeckhoven C: Genetics of personality: are we making progress? Mol Psychiatry 2003;8:840-852.

24 Caspi A, Moffitt TE, Thornton A, Freedman D: The life history calendar: a research and clinical assessment method for collecting retrospective event-history data. Int J Meth Psychiatr Res 1996;6:101-114.

25 Borkenau P, Ostendorf F: NEO-Fünf-Faktoren Inventar nach Costa und McCrae. Handanweisung. Göttingen, Hogrefe, 1993. 
26 Block J: The Q-Sort Method in Personality Assessment and Psychiatric Research. Palo Alto, Consulting Psychologist Press, 1978.

27 Zimmermann P: Structure and functions of internal working models and their role for emotion regulation. Attach Hum Dev 1999; 1:201-206.

28 Letzring TD, Block J, Funder DC: Ego-control and ego-resiliency: generalization of self-report scales based on personality descriptions from acquaintances, clinicians, and the self. J Res Pers 2005;39:395-422.

29 Weyers P, Krebs H, Janke W: Reliability and construct validity of the German version of Cloninger's Tridimensional Personality Questionnaire. Pers Indiv Differ 1995;19: 853-861.

30 Freeman B, Powell J, Ball D, Hill L, Craig I, Plomin R: DNA by mail: an inexpensive and noninvasive method for collecting DNA samples from widely dispersed populations. Behav Genet 1997;27:251-257.

31 Schoots O, Van Tol HH: The human dopamine D4 receptor repeat sequences modulate expression. Pharmacogenomics J 2003;3: 343-348.

32 Wang E, Ding Y-C, Flodman P, Kidd JR, Kidd KK, Grady DL, Ryder OA, Spence MA, Swanson JM, Moyzis RK: The genetic architecture of selection at the human dopamine receptor D4 (DRD4) gene locus. Am J Med Genet 2004;74:931-944.

33 Faul F, Erdfelder E, Lang AG, Buchner A: $\mathrm{G}^{*}$ Power 3: a flexible statistical power analysis program for the social, behavioral, and biomedical sciences. Behav Res Methods 2007;39:175-191.
34 Laucht M, Becker K, El-Faddagh M, Hohm E, Schmidt MH: Association of the DRD4 exon III polymorphism with smoking in fifteen-year-olds: a mediating role for novelty seeking? J Am Acad Child Psychol 2005;44: 477-484.

35 Szekely A, Ronai Z, Nemoda Z, Kolmann G, Gervai J, Sasvari-Szekely M: Human personality dimensions of persistence and harm avoidance associated with DRD4 and 5-HTTLPR polymorphisms. Am J Med Genet B Neuropsychiatr Genet 2004;126B:106-110.

36 Oak JN, Oldenhof J, Van Tol HHM: The dopamine D4 receptor: one decade of research. Eur J Pharmacol 2000;405:303-327.

37 Wang $\mathrm{X}$, Zhong $\mathrm{P}$, Zhen $\mathrm{Y}$ : Dopamine $\mathrm{D}_{4}$ receptors modulate GABAergic signaling in pyramidal neurons of prefrontal cortex. J Neurosci 2002;22:9185-9193.

38 Dewing P, Chiang CWK, Sinchak K, Sim H, Fernagut P-O, Kelly S, Chesselet M-F, Micevych PE, Albrecht KH, Harley VR, Vilain E: Direct regulation of adult brain function by the male-specific factor SRY. Curr Biol 2006; 16:415-420.

39 Simerly RB: Hormonal regulation of limbic and hypothalamic pathways; in Micevych PE, Hammer RP (eds): Neurobiological Effects of Sex Steroid Hormones. New York, Cambridge University Press, 1995, pp 85114.

40 Serretti A, Mandelli L: The genetics of bipolar disorder: genome 'hot regions', genes, new potential candidates and future directions. Mol Psychiatry 2008;13:742-771.
41 López-León S, Janssens ACJW, Ladd AMGZ, Del-Favero J, Claes SJ, Oostra BA, van Duijn CM: Meta-analyses of genetic studies on major depressive disorder. Mol Psychiatry 2008;13:772-785

42 Caspi A, Sugden K, Moffitt TE, Taylor A, Craig IW, Harrington H, McClay J, Mill J, Martin J, Braithwaite A, Poulton R: Influence of life stress on depression: moderation by a polymorphism in the 5 -HTT gene. Science 2003;301:386-389.

43 Hayaki J, Stein MD, Lassor JA, Herman DS, Anderson BJ: Adversity among drug users: relationship to impulsivity. Drug Alcohol Depend 2005;78:65-71.

44 Counts RM, Sacks A: Personality characteristics of divorce-prone individuals: a preliminary clinical study. Contemp Fam Ther 1986;8:111-123.

45 Ryb GE, Dischinger PC, Kufera JA, Read KM: Risk perception and impulsivity: association with risky behaviors and substance abuse disorders. Accident Anal Prev 2006; 38:567-573.

46 Cloninger CR: A systematic method for clinical description and classification of personality variants: a proposal. Arch Gen Psychiatry 1987; 44:573-588.

47 Strobel A, Brocke B, Ebstein RP: Interaktionseffekte monoamin-relevanter genetischer Polymorphismen mit Traits des TPQ. Z Differ Diagnost Psychol 2000;21:194-199.

48 Sullivan PF: Spurious genetic associations. Biol Psychiatry 2007;61:1121-1126. 